\title{
Rapid differentiation between fluconazole-sensitive and -resistant species of Candida directly from positive blood-culture bottles by real-time PCR
}

Correspondence
L. Metwally
lobna.metwally@bll.n-i.nhs.uk

Received 3 January 2007

Accepted 5 March 2007

\author{
L. Metwally, ${ }^{1}$ † G. Hogg, ${ }^{1}$ P. V. Coyle, ${ }^{1}$ R. J. Hay, ${ }^{2}$ S. Hedderwick, ${ }^{3}$ \\ B. McCloskey, ${ }^{4}$ H. J. O'Neill, ${ }^{1}$ G. M. Ong, ${ }^{1}$ G. Thompson, ${ }^{1,4}$ C. H. Webb ${ }^{1}$ \\ and R. McMullan ${ }^{1}$ \\ ${ }^{1}$ Department of Medical Microbiology, Royal Victoria Hospital, Belfast, Northern Ireland \\ ${ }^{2}$ Queen's University of Belfast, School of Medicine and Dentistry, Belfast, Northern Ireland \\ ${ }^{3}$ Department of Infectious Diseases, Royal Victoria Hospital, Belfast, Northern Ireland \\ ${ }^{4}$ Regional Intensive Care Unit, Royal Victoria Hospital, Belfast, Northern Ireland
}

\begin{abstract}
In view of both the delay in obtaining identification by conventional methods following blood-culture positivity in patients with candidaemia and the close relationship between species and fluconazole (FLC) susceptibility, early speciation of positive blood cultures has the potential to influence therapeutic decisions. The aim was to develop a rapid test to differentiate FLC-resistant from FLC-sensitive Candida species. Three TaqMan-based real-time PCR assays were developed to identify up to six Candida species directly from BacT/Alert blood-culture bottles that showed yeast cells on Gram staining at the time of initial positivity. Target sequences in the rRNA gene complex were amplified, using a consensus two-step PCR protocol, to identify Candida albicans, Candida parapsilosis, Candida tropicalis, Candida dubliniensis, Candida glabrata and Candida krusei; these are the most commonly encountered Candida species in blood cultures. The first four of these (the characteristically FLC-sensitive group) were identified in a single reaction tube using one fluorescent TaqMan probe targeting $18 \mathrm{~S}$ rRNA sequences conserved in the four species. The FLC-resistant species C. krusei and C. glabrata were detected in two further reactions, each with species-specific probes. This method was validated with clinical specimens (blood cultures) positive for yeast ( $n=33$ sets) and the results were $100 \%$ concordant with those of phenotypic identification carried out concomitantly. The reported assay significantly reduces the time required to identify the presence of C. glabrata and C. krusei in comparison with a conventional phenotypic method, from $\sim 72$ to $<3 \mathrm{~h}$, and consequently allows optimization of the antifungal regimen at an earlier stage.
\end{abstract}

\section{INTRODUCTION}

Disseminated fungal infection is a significant cause of mortality in hospitalized patients (Trick et al., 2002; Wey et al., 1988). Candida species account for between 70 and $80 \%$ of fungal bloodstream infections, and collectively represent the fourth most common group of pathogens responsible for nosocomial bloodstream infection, with a mortality rate of approximately $50 \%$ (Beck-Sague \& Jarvis, 1993; Fridkin \& Jarvis, 1996; Trick et al., 2002). Of the Candida species that cause invasive infections, Candida albicans, Candida parapsilosis, Candida tropicalis and

tPresent address: Regional Virus Laboratory, Royal Hospitals, Grosvenor Road, Belfast BT12 6BA, UK.

Abbreviations: FLC, fluconazole; ITS, internal transcribed spacer; PNAFISH, peptide nucleic acid fluorescent in situ hybridization.
Candida glabrata typically account for between 80 and $90 \%$ of isolates encountered in the clinical laboratory, although this may vary for a given clinical unit over time (Aliyu et al., 2006; Pfaller, 1996; Pfaller et al., 2001). Fluconazole (FLC), which has a relatively favourable adverse-effect profile and comparatively modest drugacquisition cost, has been reported to be as effective as amphotericin B for the treatment of candidaemia in nonneutropenic patients (Rex et al., 1994). Therefore, it is frequently prescribed as the first-line empirical antifungal agent in such patient populations.

However, C. glabrata and C. krusei possess the capacity to be resistant to FLC, and MIC values for C. krusei and C. glabrata are typically much higher than those for $C$. albicans, C. tropicalis, C. parapsilosis and C. dubliniensis (Pfaller et al., 1999). Such high MICs are not consistently 
within the achievable therapeutic range when standard FLC dosing regimens are employed. Therefore, it is logical that the availability of information at an early stage regarding the species recovered in patients with candidaemia may help physicians to select the most appropriate antifungal agent in a timely manner; this has the potential to positively impact patient outcomes while maintaining the cost-effectiveness of antifungal therapy (Garey et al., 2006).

Final identification of yeasts in positive blood cultures normally requires at least $72 \mathrm{~h}$, during which time patients receive empirical treatment. A similar time is required to complete antifungal susceptibility testing. Therefore, a test to rapidly and accurately identify Candida isolates, categorized into species groups strongly predictive of FLC susceptibility, directly from positive blood-culture bottles would be of significant clinical and therapeutic value.

Efforts have been directed toward molecular testing of Candida isolates from solid media or blood-culture bottles. These include amplification of a target gene(s) followed by a post-amplification analysis to identify the amplicons based on either electrophoretic migration or hybridization with specific nucleotide probes (Einsele et al., 1997; Elie et al., 1998; Fujita et al., 1995; Park et al., 2000; Fadda, 2000, Playford et al., 2006; Luo \& Mitchell, 2002; Shin et al., 1997; Das et al., 2006; Morace et al., 1997). These methods have shown promise in the diagnosis of fungal infections but have problems that prevent their use on a routine basis; for example, the use of nested PCR or PCR in conjunction with restriction enzyme analysis may add needless complexity to these assays.

Other investigators have demonstrated the accuracy of peptide nucleic acid fluorescent in situ hybridization (PNA-FISH) for rapid detection of C. albicans directly from blood-culture bottles (Forrest et al., 2006; Alexander et al., 2006; Wilson et al., 2005; Rigby et al., 2002; Oliveira et al., 2001). This is a rapid and relatively straightforward technique; however, this approach does not facilitate the detection of other species. Therefore, it cannot be assumed that a negative result with this test implies the presence of an FLC-resistant species, since it is unable to distinguish between, for example, C. parapsilosis and C. krusei.

We report a rapid and sensitive real-time PCR method to distinguish the typically FLC-sensitive species of Candida (C. albicans, C. tropicalis, C. parapsilosis and C. dubliniensis) from usually resistant species (C. glabrata and $C$. krusei) directly from positive blood-culture bottles which can be completed in less than $3 \mathrm{~h}$ after the initial detection by Gram staining.

\section{METHODS}

Candida isolates. American Type Culture Collection (ATCC) strains and laboratory strains identified by standard phenotypic methods were used to generate Candida species DNA templates. The strains C. albicans ATCC 90028, C. tropicalis ATCC 20336, C. glabrata ATCC 66032, C. parapsilosis ATCC 22019, C. krusei ATCC 6258 and laboratory strains of C. dubliniensis, Candida guillermondii, Candida kefyr, Candida sphaerica, Candida famata and Candida lusitaniae were obtained from the mycology laboratory, Royal Victoria Hospital, Belfast.

Clinical specimens. BacT/Alert blood-culture bottles (Organon Teknika) were normally inoculated with $5-10 \mathrm{ml}$ blood from adult patients; in the case of children and neonates, Pedi-BacT bottles were typically inoculated with $3-5 \mathrm{ml}$ and $1-2 \mathrm{ml}$, respectively, in the course of routine clinical care. Bottles were inserted into the BacT/ Alert instrument (Organon Teknika) and incubated at $37{ }^{\circ} \mathrm{C}$. Once bottles became positive, aliquots were removed for Gram staining and subsequent culturing.

A total of 33 consecutive Candida-positive blood-culture sets (20 aerobic, 15 anaerobic and six paediatric bottles) were collected from the Microbiology Laboratory, Royal Victoria Hospital, Belfast, from November 2005 to July 2006. In addition, 10 specimens from bloodculture bottles (five aerobic, four anaerobic and one paediatric) that were negative for yeast were included as negative control samples.

Routine phenotypic identification consisted of isolation of Candida species from positive blood-culture bottles by plating $50 \mu \mathrm{l}$ aliquots onto one Malt agar plate incubated at $30{ }^{\circ} \mathrm{C}$, one Malt agar plate at $37{ }^{\circ} \mathrm{C}$ and CHROMagar plates (Hardy Diagnostics) at $37{ }^{\circ} \mathrm{C}$, and subsequent identification by microscopic (germ-tube formation in horse serum) and biochemical (API Candida and/or API 32C, bioMérieux) tests.

\section{Extraction of Candida DNA}

(i) From fungal suspensions. Fungal isolates were subcultured onto Sabouraud medium (Difco) at $30^{\circ} \mathrm{C}$; yeast isolates were cultured for $48 \mathrm{~h}$ and mould isolates for $72 \mathrm{~h}$. Thereafter, fungal saline suspensions were adjusted to equivalence with the $0.5 \mathrm{McF}$ arland standard. The fungal suspensions were centrifuged at $5000 \mathrm{~g}$ for $10 \mathrm{~min}$ and then the pellet was incubated with $500 \mu \mathrm{l}$ lyticase buffer $\left[10 \mathrm{U} \mathrm{ml} \mathrm{m}^{-1}\right.$ recombinant lyticase (Sigma), $50 \mathrm{mM}$ Tris, $\mathrm{pH} 7.5,10 \mathrm{mM}$ EDTA, $28 \mathrm{mM} \beta$-mercaptoethanol] at $30{ }^{\circ} \mathrm{C}$ for $30 \mathrm{~min}$. The resultant spheroblasts were pelleted by centrifugation for $5 \mathrm{~min}$ at $5000 \mathrm{~g}$ and resuspended in buffer and proteinase K. DNA extraction was continued according to the tissue protocol in the QIAamp DNA Mini kit (Qiagen). Extracted DNA was stored at $-20{ }^{\circ} \mathrm{C}$.

(ii) From blood-culture bottles. Aliquots from all blood-culture $(n=43)$ bottles were subjected to DNA extraction by two established protocols.

QIAamp extraction (method A). The total DNA from $0.2 \mathrm{ml}$ of yeastpositive BacT/Alert blood-culture medium was purified according to the manufacturer's instructions by using the recombinant lyticase enzyme and QIAamp blood kit (Qiagen) and eluted in $0.1 \mathrm{ml}$ elution buffer.

Benzyl alcohol/guanidine hydrochloride organic extraction (method B). A published method was adopted (Fredricks \& Relman, 1998). The extract was stored at $-20{ }^{\circ} \mathrm{C}$ until it was used for PCR amplification.

\section{Real-time PCR assay}

(i) Oligonucleotide design. Primers used to amplify all typically FLC-sensitive Candida species have been published previously (White et al., 2003; Shin et al., 1999), whereas those for C. krusei and C. glabrata were designed in-house using the Lasergene software program, version 5 (DNAstar) (Table 1). Publically available GenBank sequences for the rRNA genes of different Candida species were aligned and inspected for regions of conserved and variable 
Table 1. Primers and probes used in this study

\begin{tabular}{|c|c|c|c|}
\hline Primer & Sequence $\left(5^{\prime} \rightarrow 3^{\prime}\right)^{\star}$ & Product size & Target gene $(s)$ \\
\hline \multicolumn{4}{|c|}{ FLC sensitive } \\
\hline Can 1c & F-CTCGTAGTTGAACCTTGG & $140 \mathrm{bp}$ & $18 \mathrm{~S}$ \\
\hline Can $1 \mathrm{~d}$ & R-GCCTGCTTTGAACACTCT & & \\
\hline Can p1 & 6FAM-TTTTGATGCGTACTGGACCC-BHQ1 & & \\
\hline \multicolumn{4}{|c|}{ C. glabrata } \\
\hline Gla1c & F-CCTGTTTGAGCGTCATTTCC & $229 \mathrm{bp}$ & ITS1, 5.8S, ITS2 \\
\hline Gla1d & R-AGCACGCACAAAACACTCACTTAT & & \\
\hline Gla p1 & VIC-TAGGTTTTACCAACTCGGTGTTGAT-BHQ1 & & \\
\hline \multicolumn{4}{|c|}{ C. krusei } \\
\hline Kru 1c & F-CCTGTTTGAGCGTCATTTCC & $219 \mathrm{bp}$ & ITS1, 5.8S, ITS2 \\
\hline Kru 1d & R-CCTGCTTTGAACACTCTAA & & \\
\hline Kru p1 & 6FAM-AGCTGGCCGAGCGAACTAGACTTTT-TAMRA & & \\
\hline
\end{tabular}

${ }^{\star} \mathrm{F}$, forward primer; $\mathrm{R}$, reverse primer.

sequences by the CLUSTAL_W tool using the Lasergene software program. Regions specific for the chosen fungal species were selected for primer targeting of C. glabrata and C. krusei. The assay for the FLC-susceptible group utilized universal fungal primers can 1c (forward primer) and can 1d (reverse primer) and an FLC-sensitive species-specific probe to amplify a conserved portion of the $18 \mathrm{~S}$ rRNA sequences, whereas the sequences of probes for C. glabrata and C. krusei assays were specific to the variable sequences of the internal transcribed spacer (ITS) 2 region. The probe for detection of FLCsensitive Candida species has been published elsewhere (White et al., 2003); however, it was modified by TaqMan chemistry, utilizing a non-fluorescent quencher (BHQ1) at it $3^{\prime}$ end. Primers and probes were purchased from Sigma-Genosys.

(ii) PCR amplification. Real-time PCR was performed with $2 \mu \mathrm{l}$ template DNA in a total reaction volume of $10 \mu$ l containing $1 \times$ PCR buffer (Promega), $3.5 \mathrm{mM} \mathrm{MgCl}_{2}, 0.2 \mathrm{mM}$ of each deoxynucleoside

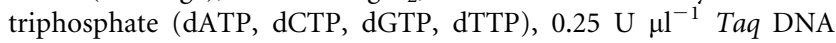
polymerase (Promega), $0.2 \mu \mathrm{M}$ of primers for the rRNA genes, $0.2 \mu \mathrm{M}$ TaqMan probe, $1 \mu \mathrm{M}$ 5-carboxy-X-rhodamine (ROX) passive reference dye (Invitrogen) and $2 \mu \mathrm{g} \mathrm{BSA} \mu \mathrm{l}^{-1}$ (Sigma). The ABI 7000 Sequence Detection System (Applied Biosystems) was switched on $30 \mathrm{~min}$ prior to use. Each sample was run in duplicate in standard PCR strips but with optical PCR lids using the following PCR cycling conditions: after an initial denaturation step of $3 \mathrm{~min}$ at $95{ }^{\circ} \mathrm{C}$, a twostep PCR procedure was used consisting of $30 \mathrm{~s}$ at $95{ }^{\circ} \mathrm{C}$ and $1 \mathrm{~min}$ at $60{ }^{\circ} \mathrm{C}$ for 40 cycles.

A negative control consisting of the reaction mixture and water (in place of template DNA) was added in each run. In addition to negative controls, $1 \mathrm{ml}$ of medium withdrawn from a sterile bloodculture bottle was spiked with the yeast under test $\left(<100\right.$ c.f.u. $\left.\mathrm{ml}^{-1}\right)$ and the sample was included as a positive extraction control.

Data were obtained during the annealing period. Fluorescence was measured once every cycle immediately after the $60{ }^{\circ} \mathrm{C}$ incubation (extension step). Fluorescence curves were analysed with the ABI 7000 Sequence Detection System software and results were expressed by determination of the threshold of detection, $C_{\mathrm{T}}$, which marked the cycle at which the fluorescence of the sample became significantly different from the baseline signal. A sample was regarded as positive when the ABI 7000 software determined a $C_{\mathrm{T}}$ in the quantification analysis screen.

(iii) Synthetic controls. To establish the analytical sensitivity of the assay, we created a plasmid containing Candida DNA amplicons by using the TOPO TA cloning procedures with a pCR4-TOPO vector (Invitrogen). Insertion of the correct amplicons was confirmed by nucleotide sequencing using the Thermo Sequenase fluorescently labelled primer cycle sequencing kit with 7-deaza-dGTP (Amersham Pharmacia Biotech). The purified recombinant plasmid was quantified using the Amersham Gene Quant II DNA/RNA spectrophotometer (Amersham Pharmacia Biotech). The pre-quantified plasmid standards were diluted in nuclease-free water and stored at $-20{ }^{\circ} \mathrm{C}$.

Assay specificity. The analytical specificity of the three developed assays was determined by testing a panel of archived microorganisms, identified by standard methods, including bacterial species (Enterobacter cloacae, Escherichia coli, Staphylococcus aureus, Proteus mirabilis and Moraxella catarrhalis), different Candida species (C. albicans, C. tropicalis, C. parapsilosis, C. glabrata, C. krusei, C. lusitaniae, C. kefyr, C. guillermondii and C. sphaerica), non-Candida yeast strains of Cryptococcus laurentii, Cryptococcus neoformans, Geotrichum species, Rhodotorula rubra, Saccharomyces cerevisiae and Trichosporon asahii, as well as strains of filamentous fungi such as Penicillium viridicatum, Alternaria alternata, Aspergillus niger, Fusarium species, Rhizopus, Aspergillus fumigatus and Cladosporium species. The identity of all fungal isolates was confirmed phenotypically by the mycology laboratory, Royal Hospitals Trust, Belfast.

Analytical sensitivity. Tenfold dilutions (typically in the range $10^{-1}-10^{-12}$ ) were made by serial dilution of Candida plasmid DNA with nuclease-free water. The sensitivity of the assay was determined by carrying out real-time PCR on serial tenfold dilutions of plasmid DNA and recording the detection end point copy number.

Quality control. Each reaction was carried out in duplicate. Bloodculture specimens that were inoculated with yeast cells were used as positive controls for each sample run. Carryover contamination was reduced by using aerosol-resistant pipette tips and separate laboratory areas for DNA sample preparation and PCR amplification, along with other standard contamination precautions.

Nucleotide sequence accession numbers. The database accession numbers of the existing GenBank depositions investigated were as follows: C. albicans, M60302; C. parapsilosis, AY055855; C. tropicalis, M55527; C. krusei, M60305; C. glabrata, M60311; C. dubliniensis, X99399; A. fumigatus, M60300; Aspergillus terreus, X78540; A. niger, X78538; Aspergillus flavus, X78537; and Aspergillus nidulans, X78539. 


\section{RESULTS}

\section{Extraction of Candida DNA}

Sodium polyanetholesulfonate (SPS) is a common component in commercially available blood-culture media and is a potent PCR inhibitor. We found that the organic extraction method, with benzyl alcohol and guanidine hydrochloride, was able to overcome its effect and the effects of other inhibitory substances that were present in both aerobic and anaerobic bottles, such as haemoglobin and lactoferrin. We were able to obtain PCR products from all blood-culture bottles extracted by this method. On the other hand, when we used the enzymic lysis method (followed by the Qiagen extraction protocol), the inhibitory effect of SPS could be overcome only by diluting the extracts.

\section{Assay specificity}

The probe for the FLC-sensitive group hybridized appropriately with C. albicans, C. tropicalis, C. parapsilosis and C. dubliniensis, but did not hybridize with DNA from other species of Candida, such as C. famata, C. kefyr, C. guillermondii, C. sphaerica, C. lusitaniae, C. krusei and C. glabrata, or with the bacteria and other fungi that were tested. The C. krusei probe hybridized only with C. krusei and the C. glabrata probe only with C. glabrata.

\section{Assay sensitivity}

The sensitivity of the real-time PCR assay was determined using serial dilutions of Candida species plasmid DNA with known copy numbers. The detection end point was $10^{-9}$ for the three assays. As there are more than 100 copies of the ribosomal genes per yeast cell, the sensitivities of the three assays equated to no more than one Candida cell per reaction. The end point copy numbers for each of the three assays were:

FLC-sensitive Candida assay, 160 copies $\mathrm{ml}^{-1}$

C. glabrata assay, 600 copies $\mathrm{ml}^{-1}$

C. krusei assay, 280 copies $\mathrm{ml}^{-1}$

\section{Assay verification with clinical specimens}

Routine subculture and phenotypic identification of 33 yeast-positive blood-culture bottles revealed 26 as $C$. albicans, three as C. parapsilosis, one as C. dubliniensis and three as C. glabrata; there were no isolates of $C$. krusei or $C$. tropicalis in any of the clinical specimens obtained.

Among the 33 positive blood-culture bottles containing yeasts, two were mixed with coagulase-negative staphylococci. Coexisting bacteria in these specimens did not produce any products or did not interfere with yeast identification. There were no episodes of mixed candidaemias among the blood-culture bottles analysed.

There was $100 \%$ agreement between the results obtained by the real-time PCR method and those of the conventional techniques in routine use (Table 2). All blood cultures $(n=10)$ that had shown no growth after 7 days incubation in the BacT/Alert instrument were negative by real-time PCR.

\section{DISCUSSION}

Widespread use of FLC in the prophylaxis and treatment of candidosis has contributed to the emergence of Candida infections caused by FLC-resistant species. Given the fulminant and frequently fatal outcome of acute disseminated candidosis, the rapid discrimination of azolesensitive from -resistant species has a critical role in the timely implementation of targeted antifungal drug therapy.

Extant, culture-based, phenotypic methods to identify Candida species from positive blood-culture bottles require at least $24 \mathrm{~h}$ following initial positivity by Gram staining to obtain positive growth on solid culture medium. If germtube formation can be seen on microscopic examination, a presumptive identification of $C$. albicans may be made; however, a further $48 \mathrm{~h}$ is usually needed to speciate nonalbicans isolates by sugar assimilation strip or fermentation tests (Dooley et al., 1994); this amounts to a total of $72 \mathrm{~h}$ following blood-culture positivity to reach a final identification. Although CHROMagar Candida (Hardy Diagnostics) can be helpful in providing early presumptive speciation of some common Candida species, based on a chromogenic indicator, such identification is not definitive; furthermore, some species produce subtle, indeterminate colour changes. Even the $4 \mathrm{~h}$ RapID test (Innovative Diagnostics) still requires a time of at least 1 day after initial blood-culture positivity to obtain pure isolated colonies from which to inoculate test wells for analysis (Espinel-Ingroff et al., 1998).

At the molecular level, fungal rRNA sequence variation offers an alternative to phenotypic identification for detection and identification of yeasts. The multicopy ribosomal gene complex is a useful target for PCR assays because of the enhanced sensitivity attributable to its multiple copies, the high sequence conservation of its $18 \mathrm{~S}$, $5.8 \mathrm{~S}$ and $28 \mathrm{~S}$ regions (for panfungal primers), and the high variability of its intervening ITS regions (for speciesspecific probes) with high interspecies and low intraspecies heterogeneity. As a result, molecular biology-based diagnostic methods that use rRNA sequences have been used to overcome the problems of sensitivity, specificity and delay encountered with conventional methods (Moreira-Oliveira et al., 2005; Ellepola \& Morrison, 2005; Klingspor \& Jalal, 2006; Maaroufi et al., 2003).

Although other investigators have employed molecular techniques for yeast identification from positive bloodculture bottles, these techniques have been associated with several problems, ranging from inability to discriminate $C$. glabrata (a potentially FLC-resistant species) to timeconsuming, labour-intensive and costly methods, some of which require equipment which is not readily available in a typical molecular-diagnostic laboratory (Chang et al., 2001; Selvarangan et al., 2003). We believe that we have 
Table 2. Comparison between results of phenotypic identification and those of the real-time PCR assay

Abbreviations: A, aerobic; AN, anaerobic; P, paediatric; CNS, coagulase-negative staphylococcus; CPS, coagulase-positive staphylococcus.

\begin{tabular}{|c|c|c|c|c|}
\hline $\begin{array}{l}\text { Blood cul- } \\
\text { ture set no. }\end{array}$ & $\begin{array}{l}\text { Type of bottle } \\
\text { tested }\end{array}$ & Phenotypic identification & Assay results & $\begin{array}{l}\text { Agreement/disagreement between } \\
\text { phenotypic identification and PCR }\end{array}$ \\
\hline 1 & A, AN & C. albicans & Positive by assay 1 only* & Agreement \\
\hline 2 & $\mathrm{P}$ & C. albicans & Positive by assay 1 only* & Agreement \\
\hline 3 & $\mathrm{~A}, \mathrm{AN}$ & C. parapsilosis & Positive by assay 1 only* & Agreement \\
\hline 4 & A & C. albicans & Positive by assay 1 only* & Agreement \\
\hline 5 & $\mathrm{~A}$ & C. parapsilosis & Positive by assay 1 only* & Agreement \\
\hline 6 & AN & C. albicans & Positive by assay 1 only* & Agreement \\
\hline 7 & $\mathrm{P}$ & C. albicans & Positive by assay 1 only* & Agreement \\
\hline 8 & $\mathrm{~A}, \mathrm{AN}$ & C. albicans & Positive by assay 1 only* & Agreement \\
\hline 9 & A & C. dubliniensis & Positive by assay 1 only* & Agreement \\
\hline 10 & AN & C. albicans & Positive by assay 1 only* & Agreement \\
\hline 11 & A & C. albicans & Positive by assay 1 only* & Agreement \\
\hline 12 & A & C. albicans & Positive by assay 1 only* & Agreement \\
\hline 13 & AN & C. albicans & Positive by assay 1 only* & Agreement \\
\hline 14 & A, AN & C. albicans & Positive by assay 1 only* & Agreement \\
\hline 15 & AN & C. glabrata & Positive by C. glabrata assay only & Agreement \\
\hline 16 & A & C. albicans & Positive by assay 1 only* & Agreement \\
\hline 17 & A, AN & C. albicans & Positive by assay 1 only* & Agreement \\
\hline 18 & A & C. albicans & Positive by assay 1 only* & Agreement \\
\hline 19 & AN & C. albicans & Positive by assay 1 only* & Agreement \\
\hline 20 & $\mathrm{P}$ & C. albicans & Positive by assay 1 only* & Agreement \\
\hline 21 & A, AN & C. albicans & Positive by assay 1 only* & Agreement \\
\hline 22 & $\mathrm{P}$ & C. albicans & Positive by assay 1 only* & Agreement \\
\hline 23 & A & C. parapsilosis & Positive by assay 1 only* & Agreement \\
\hline 24 & $\mathrm{~A}, \mathrm{AN}$ & C. albicans & Positive by assay 1 only* & Agreement \\
\hline 25 & $\mathrm{P}$ & C. albicans & Positive by assay 1 only* & Agreement \\
\hline 26 & A & C. albicans & Positive by assay 1 only* & Agreement \\
\hline 27 & $\mathrm{P}$ & C. albicans & Positive by assay 1 only* & Agreement \\
\hline 28 & AN & C. albicans & Positive by assay 1 only* & Agreement \\
\hline 29 & $\mathrm{~A}$ & C. glabrata & Positive by C. glabrata assay only & Agreement \\
\hline 30 & AN & C. albicans & Positive by assay 1 only* & Agreement \\
\hline 31 & A, AN & C. glabrata & Positive by C. glabrata assay only & Agreement \\
\hline 32 & A & C. albicans & Positive by assay 1 only* & Agreement \\
\hline 33 & A & C. albicans & Positive by assay 1 only* & Agreement \\
\hline 34 & A & CNS & Negative by all assays & Agreement \\
\hline 35 & AN & Streptococcus mitis & Negative by all assays & Agreement \\
\hline 36 & $\mathrm{~A}$ & E. coli & Negative by all assays & Agreement \\
\hline 37 & $\mathrm{P}$ & CNS & Negative by all assays & Agreement \\
\hline 38 & $\mathrm{~A}$ & CNS & Negative by all assays & Agreement \\
\hline 39 & AN & CPS & Negative by all assays & Agreement \\
\hline 40 & AN & Bacillus species & Negative by all assays & Agreement \\
\hline 41 & AN & E. coli & Negative by all assays & Agreement \\
\hline 42 & $\mathrm{~A}$ & CNS & Negative by all assays & Agreement \\
\hline 43 & A & CNS & Negative by all assays & Agreement \\
\hline
\end{tabular}

${ }^{*}$ Assay for FLC-sensitive Candida species.

overcome many such barriers in developing the current method. For example, the Candida species are grouped such that those predictive of FLC susceptibility may be identified in a single assay. As this assay will be positive in the majority of circumstances, it can serve as a rapid test to guide the choice of antifungal drug even before the other two described assays are carried out.
The PNA-FISH technique also targets rRNA, although its evaluation has not extended beyond a C. albicans-specific probe in the published literature (Forrest et al., 2006; Alexander et al., 2006; Wilson et al., 2005; Rigby et al., 2002; Oliveira et al., 2001). While this rapid test has proven reliability in a multicentre trial, it cannot distinguish between the non-albicans species; since this group 
represents a growing proportion of candidaemias, such deficiencies may not be acceptable. As a result, one could be inclined to assume that specimens testing negative represent FLC-resistant species, which will be inappropriate in a large number of instances, depending on the epidemiology of the institution. This has the potential to threaten both the cost-effectiveness of this test and prudent antifungal stewardship. Furthermore, this technique is incapable of discriminating mixed candidaemias (containing more than one Candida species). One may, therefore, wrongly conclude that $C$. albicans is the only species present in a mixture of $C$. albicans and C. krusei or $C$. glabrata; this could lead to inadequate initial therapy and pose a risk to patient outcomes.

TaqMan probes were used in the real-time PCR assay we describe to discriminate the typically FLC-sensitive Candida species (C. albicans, C. tropicalis, C. parapsilosis and $C$. dubliniensis) from the more frequently FLCresistant species (C. glabrata and C. krusei); this allowed both a reduction in the number of sample-manipulation steps that needed to be performed and the detection of four Candida species in the same reaction tube. We favour the organic extraction method to the enzymic lysis method, as described, since it was better able to overcome the effects of inhibitors present in blood-culture bottles. The organic extraction method has been used successfully by Fredricks \& Relman (1998) to purify bacterial DNA from inoculated blood-culture bottles.

Our study has some limitations. First, the number of positive blood cultures was limited by the incidence of candidaemia in our institution during the study; nonetheless, the available results provide robust pilot data. Second, most of the isolates that were collected were $C$. albicans and no C. krusei was isolated during the study period. Although this is not entirely surprising, given our knowledge of the pattern of species causing candidaemia (McMullan et al., 2002), it is disappointing that the C. krusei assay could not be verified using clinical specimens. However, this does not substantially threaten the potential utility of the assay. Third, since this was a single-institution study, only one blood-culture system was in use; hence, the applicability of this technique, particularly the extraction step, cannot be assured for other systems.

Furthermore, no blood-culture bottles included in the study contained more than one yeast species. It would be interesting to evaluate our hypothesis that the assays would be capable of simultaneously amplifying different species so that in mixed blood cultures, more than one Candida species would be detectable. Finally, we were unable to demonstrate any specific clinical benefit or the costeffectiveness of this assay, because of the size and scope of the dataset. Although the cost-effectiveness of the PNA-FISH technique has been suggested elsewhere (Forrest et al., 2006; Alexander et al., 2006), generalization of this suggestion is not universally appropriate, since cost-effectiveness is critically dependent upon the empirical antifungal-prescribing preferences of a given institution.

Currently, our system relies on identifying the six Candida species in three reaction tubes in a single run. Because we are using the same cycle parameters for the three assays, there is potential for multiplexing the three probes in a single reaction tube. C. glabrata and C. krusei probes could be labelled with other fluorescent dyes that have similar excitation wavelengths but different emission wavelengths from those used in the FLC-sensitive group probe, so identification and discrimination of the six species could be performed in one tube. Therefore, further modifications to these assays have the potential to facilitate even greater ease of use.

Nonetheless, with the clinical specimens to which they were applied, our assays demonstrated $100 \%$ concordance with phenotypic assays, and significantly reduced the time required to accurately identify the presence of typically FLC-resistant species, from $\sim 72$ to $<3 \mathrm{~h}$. Furthermore, the equipment required to perform these assays is likely to be readily available in a routine molecular-diagnostic laboratory, and consequently there is a real potential that these assays could be applied to this clinical diagnostic problem.

\section{ACKNOWLEDGEMENTS}

This work was supported by the Northern Ireland Health and Personal Social Services Research and Development Office as part of commissioned research under the antimicrobial resistance action plan. We are grateful to $\mathrm{Mr}$ Jim Walker at the mycology laboratory, Royal Victoria Hospital, Belfast, for help in identifying the fungal isolates used in this study.

\section{REFERENCES}

Alexander, B. D., Ashley, E. D., Reller, L. B. \& Reed, S. D. (2006). Cost savings with implementation of PNA FISH testing for identification of Candida albicans in blood cultures. Diagn Microbiol Infect Dis 54, 277-282.

Aliyu, S. H., Enoch, D. A., Abubakar, I. I., Ali, R., Carmichael, A. J., Farrington, M. \& Lever, M. L. (2006). Candidaemia in a large teaching hospital: a clinical audit. QJM 99, 655-663.

Beck-Sague, C. \& Jarvis, W. R. (1993). Secular trends in the epidemiology of nosocomial fungal infections in the United States, 1980-1990. J Infect Dis 167, 1247-1251.

Chang, H. C., Leaw, S. N., Huang, A. H., Wu, T. L. \& Chang, T. C. (2001). Rapid identification of yeasts in positive blood cultures by a multiplex PCR method. J Clin Microbiol 39, 3466-3471.

Das, S., Brown, T. M., Kellar, K. L., Holloway, B. P. \& Morrison, C. J. (2006). DNA probes for the rapid identification of medically important Candida species using a multianalyte profiling system. FEMS Immunol Med Microbiol 46, 244-250.

Dooley, D. P., Beckius, M. L. \& Jeffrey, B. S. (1994). Misidentification of clinical yeast isolates by using the updated Vitek Yeast Biochemical Card. J Clin Microbiol 32, 2889-2892.

Einsele, H., Hebart, H., Roller, G., Loffler, J., Rothenhofer, I., Muller, C. A., Bowden, R. A., van Burik, J., Engelhard, D. \& other authors 
(1997). Detection and identification of fungal pathogens in blood by using molecular probes. J Clin Microbiol 35, 1353-1360.

Elie, C. M., Lott, T. J., Reiss, E. \& Morrison, C. J. (1998). Rapid identification of Candida species with species-specific DNA probes. $J$ Clin Microbiol 36, 3260-3265.

Ellepola, A. N. \& Morrison, C. J. (2005). Laboratory diagnosis of invasive candidiasis. J Microbiol 43, 65-84.

Espinel-Ingroff, A., Stockman, L., Roberts, G., Pincus, D., Pollack, J. \& Marler, J. (1998). Comparison of RapID yeast plus system with API 20C system for identification of common, new, and emerging yeast pathogens. J Clin Microbiol 36, 883-886.

Fadda, G. (2000). Reverse cross blot hybridization assay for rapid detection of PCR-amplified DNA from Candida species, Cryptococcus neoformans, and Saccharomyces cerevisiae in clinical samples. J Clin Microbiol 38, 1609-1614.

Forrest, G. N., Mankes, K., Jabra-Rizk, M. A., Weekes, E., Johnson, J. K., Lincalis, D. P. \& Venezia, R. A. (2006). Peptide nucleic acid fluorescence in situ hybridization-based identification of Candida albicans and its impact on mortality and antifungal therapy costs. $J$ Clin Microbiol 44, 3381-3383.

Fredricks, D. N. \& Relman, D. A. (1998). Improved amplification of microbial DNA from blood cultures by removal of the PCR inhibitor sodium polyanetholesulfonate. J Clin Microbiol 36, 2810-2816.

Fridkin, S. K. \& Jarvis, W. R. (1996). Epidemiology of nosocomial fungal infections. Clin Microbiol Rev 9, 499-511.

Fujita, S., Lasker, B. A., Lott, T. J., Reiss, E. \& Morrison, C. J. (1995). Microtitration plate enzyme immunoassay to detect PCR-amplified DNA from Candida species in blood. J Clin Microbiol 33, 962-967.

Garey, K. W., Rege, M., Pai, M. P., Mingo, D. E., Suda, K. J., Turpin, R. S. \& Bearden, D. T. (2006). Time to initiation of fluconazole therapy impacts mortality in patients with candidemia: a multiinstitutional study. Clin Infect Dis 43, 25-31.

Klingspor, L. \& Jalal, S. (2006). Molecular detection and identification of Candida and Aspergillus spp. from clinical samples using real-time PCR. Clin Microbiol Infect 12, 745-753.

Luo, G. \& Mitchell, T. G. (2002). Rapid identification of pathogenic fungi directly from cultures by using multiplex PCR. J Clin Microbiol 40, 2860-2865.

Maaroufi, Y., Heymans, C., De-Bruyne, J. M., Duchateau, V., Rodriguez-Villalobos, H., Aoun, M. \& Crokaert, F. (2003). Rapid detection of Candida albicans in clinical blood samples by using a TaqMan-based PCR assay. J Clin Microbiol 41, 3293-3298.

McMullan, R., McClurg, R., Xu, J., Moore, J. E., Millar, B. C., Crowe, M. \& Hedderwick, S. (2002). Trends in the epidemiology of Candida bloodstream infections in Northern Ireland between January 1984 and December 2000. J Infect 45, 25-28.

Morace, G., Sanguinetti, M., Posteraro, B., Lo Cascio, G. \& Fadda, G. (1997). Identification of various medically important Candida species in clinical specimens by PCR-restriction enzyme analysis. J Clin Microbiol 35, 667-672.

Moreira-Oliveira, M. S., Mikami, Y., Miyaji, M., Imai, T., Schreiber, A. Z. \& Moretti, M. L. (2005). Diagnosis of candidemia by polymerase chain reaction and blood culture: prospective study in a highrisk population and identification of variables associated with development of candidemia. Eur J Clin Microbiol Infect Dis 24, 721-726.

Oliveira, K., Haase, G., Kurtzman, C., Hyldig-Nielsen, J. J. \& Stender, H. (2001). Differentiation of Candida albicans and
Candida dubliniensis by fluorescent in situ hybridization with peptide nucleic acid probes. J Clin Microbiol 39, 4138-4141.

Park, S., Wong, M., Marras, S. A. E., Cross, E. W., Kiehn, T. E., Chaturvedi, V., Tyagi, S. \& Perlin, D. S. (2000). Rapid identification of Candida dubliniensis using a species-specific molecular beacon. J Clin Microbiol 38, 2829-2836.

Pfaller, M. A. (1996). Nosocomial candidiasis: emerging species, reservoirs, and modes of transmission. Clin Infect Dis 22 (Suppl. 2), S89-S94.

Pfaller, M. A., Messer, S. A., Hollis, R. J., Jones, R. N., Doern, G. V., Brandt, M. E. \& Hajjeh, R. A. (1999). Trends in species distribution and susceptibility to fluconazole among blood stream isolates of Candida species in the United States. Diagn Microbiol Infect Dis 33, 217-222.

Pfaller, M. A., Diekema, D. J., Jones, R. N., Sader, H. S., Fluit, A. C., Hollis, R. J. \& Messer, S. A. (2001). International surveillance of bloodstream infections due to Candida species: frequency of occurrence and in vitro susceptibilities to fluconazole, ravuconazole, and voriconazole of isolates collected from 1997 through 1999 in the SENTRY Antimicrobial Surveillance Program. J Clin Microbiol 39, 3254-3259.

Playford, E. G., Kong, F., Sun, Y., Wang, H., Halliday, C. \& Sorrell, T. C. (2006). Simultaneous detection and identification of Candida, Aspergillus, and Cryptococcus species by reverse line blot hybridization. J Clin Microbiol 44, 876-880.

Rex, J. H., Bennett, J. E., Sugar, A. M., Pappas, P. G., van der Horst, C. M., Edwards, J. E., Washburn, R. G., Scheld, W. M., Karchmer, A. W. \& other authors (1994). A randomized trial comparing fluconazole with amphotericin B for the treatment of candidaemia in patients without neutropenia. $N$ Engl J Med 331, 1325-1330.

Rigby, S., Procop, G. W., Haase, G., Wilson, D., Hall, G., Kurtzman, C., Oliveira, K., Von Oy, S., Hyldig-Nielsen, J. J. \& other authors (2002). Fluorescence in situ hybridization with peptide nucleic acid probes for rapid identification of Candida albicans directly from blood culture bottles. J Clin Microbiol 40, 2182-2186.

Selvarangan, R., Bui, U., Limaye, A. P. \& Cookson, B. T. (2003). Rapid identification of commonly encountered Candida species directly from blood culture bottles. J Clin Microbiol 41, 5660-5664.

Shin, J. H., Nolte, F. S. \& Morrison, C. J. (1997). Rapid identification of Candida species in blood cultures by a clinically useful PCR method. J Clin Microbiol 35, 1454-1459.

Shin, J. H., Nolte, F. S., Holloway, B. P. \& Morrison, C. J. (1999). Rapid identification of up to three Candida species in a single reaction tube by a $5^{\prime}$ exonuclease assay using fluorescent DNA probes. J Clin Microbiol 37, 165-170.

Trick, W. E., Fridkin, S. K., Edwards, J. R., Hajjeh, R. A. \& Gaynes, R. P. (2002). Secular trend of hospital-acquired candidaemia among intensive care unit patients in the United States during 1989-1999. Clin Infect Dis 35, 627-630.

Wey, S. B., Mori, M., Pfaller, M. A., Woolson, R. F. \& Wenzel, R. P. (1988). Hospital-acquired candidemia. The attributable mortality and excess length of stay. Arch Intern Med 148, 2642-2645.

White, P. L., Shetty, A. \& Barnes, R. A. (2003). Detection of seven Candida species using the Light-Cycler system. J Med Microbiol 52, 229-238.

Wilson, D. A., Joyce, M. J., Hall, L. S., Reller, L. B., Roberts, G. D., Hall, G. S., Alexander, B. D. \& Procop, G. W. (2005). Multicenter evaluation of a Candida albicans peptide nucleic acid fluorescent in situ hybridization probe for characterization of yeast isolates from blood cultures. J Clin Microbiol 43, 2909-2912. 